\title{
Review of the Operation of the Mental Health Act 2001
}

\section{Findings and Conclusions}

\author{
May 2007
}

AN ROINN

SLÁINTE

AGUS LEANAí 



\section{TABLE OF CONTENTS}

FOREWORD BY MINISTER OF STATE .........................................................

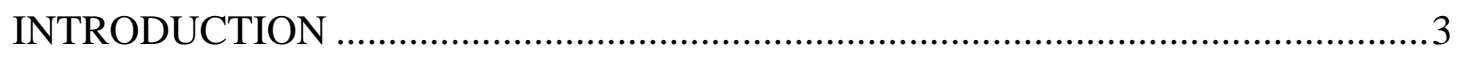

PART 1: PRELIMINARY AND GENERAL …....................................................

PART 2: INVOLUNTARY ADMISSION OF PERSONS TO APPROVED

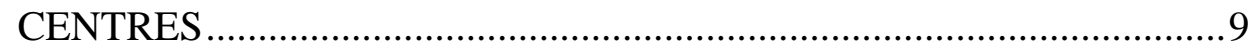

PART 3: INDEPENDENT REVIEW OF DETENTION ......................................2

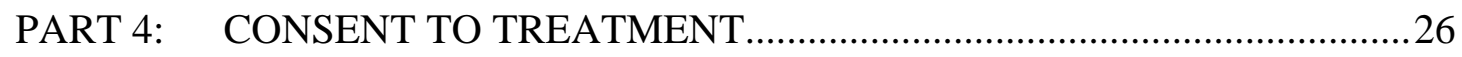

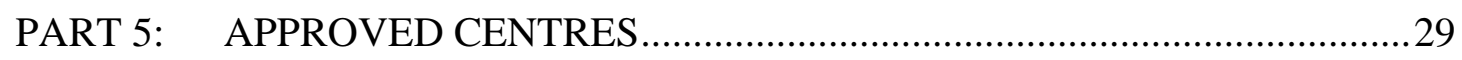

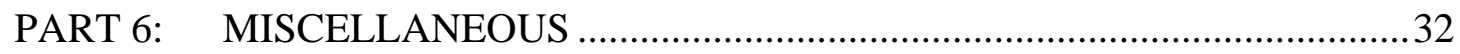

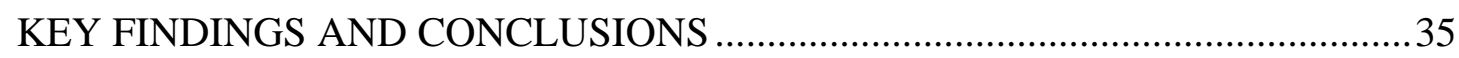

APPENDIX 1: LIST OF SUBMISSIONS RECEIVED ...........................................

APPENDIX 2: TIMELINE FOR THE INTRODUCTION OF THE MENTAL HEALTH ACT 2001.....................................................................ii

APPENDIX 3: MENTAL HEALTH TRIBUNAL STATISTICS .......................... iii 



\section{FOREWORD BY MINISTER OF STATE}

I am pleased to present this review of the operation of the Mental Health Act 2001, carried out in accordance with section 75 of the Act.

The Mental Health Act 2001 is the most significant piece of mental health legislation in Ireland in the past 60 years. It provides important safeguards to people who are involuntarily admitted by ensuring that all admission and renewal orders are subject to automatic and independent review by a Mental Health Tribunal. The Act also established the Mental Health Commission which is responsible for promoting, encouraging and fostering the establishment of high standards and good practices in the delivery of mental health services and taking all reasonable steps to protect the interests of persons detained in approved centres.

Over the past five years since the commencement of the phased implementation of the Mental Health Act 2001, significant progress has been made in improving the services provided to people with mental illness. These real improvements would not have been possible without the commitment and support of staff in the mental health services, the Health Service Executive, the Mental Health Commission and service users.

Another significant development was the publication of "A Vision for Change", the Report of the Expert Group on Mental Health Policy, in January 2006. The Report provides a framework with a set of values and principles that will guide the development of a modern, high quality mental health service over a $7-10$ year period. The future direction and delivery of all aspects of our mental health services are covered in the report.

Reform of the health sector and the establishment of the Health Service Executive have resulted in new national and local structures for the management and delivery of mental health services. The influence of service users has increased considerably with the greater availability of advocacy services and service user involvement at national and local level. 
Finally, I wish to thank all of those who contributed to this review and the staff of the Mental Health Division of my Department for their work in compiling this report.

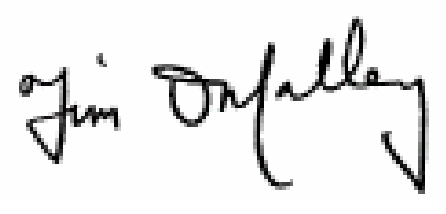

\section{Tim O'Malley}

Minister of State at the Department of Health and Children

with Special Responsibility for Mental Health 


\section{INTRODUCTION}

The Mental Health Act 2001 replaces the Mental Treatment Acts 1945-61 which provided the statutory framework for the detention of people with mental illness and the administration of psychiatric services for over 50 years.

The 2001 Act was introduced on a phased basis to allow for the necessary preparatory work to be undertaken. In March 2002 sections 1 to 5, 7, and 31 to 55 were commenced with effect from the 5 April 2002 (Establishment Day). This allowed for the establishment of the Mental Health Commission and the Inspector of Mental Health Services to replace the Inspector of Mental Hospitals.

Recruitment and training of Mental Health Tribunal members, patient legal representatives, consultants providing second opinions and administrative staff were required before Part 2 of the Act could commence. Extensive discussions were also held with all stakeholders.

The remaining provisions of the Mental Health Act 2001 (Parts 2, 4, 5 and 6) were commenced on the 1 November 2006, following close cooperation and liaison between the Department of Health and Children, the Health Service Executive and the Mental Health Commission. These parts provided for the involuntary admission of persons to approved centres, replacing the provisions of the Mental Treatment Acts 1945 to 1961, and provided for an independent review of detention, consent to treatment, registration of approved centres by the Mental Health Commission and other miscellaneous provisions.

The Mental Health Act 2001 brings Irish mental health law into compliance with international conventions. The commencement of the full provisions of the Act has been welcomed by the Mental Health Commission, service providers and service users.

Section 75 of the Mental Health Act 2001 states: "The Minister shall, not later than 5 years after the establishment day, carry out a review of the operation of this Act and shall make a report to each House of the Oireachtas of his or her findings and conclusions resulting from the review". The establishment day was the 5 April 2002. 
As part of the review, the Department of Health and Children met with the Health Service Executive and the Mental Health Commission on a number of occasions to discuss matters arising from the operation of the Act. Submissions were also requested from a range of stakeholders (a list of the stakeholders who made submissions is at Appendix 1).

The limited timeframe for the review did not allow for a comprehensive review as the full provisions of the Act have only been in operation since 1 November 2006.

Some of the submissions received raised matters which have been or are being addressed by the Mental Health Commission and service providers. Submissions also raised operational service matters relevant to the Health Service Executive, the Mental Health Commission and service providers. They are not dealt with as part of this review of the Act but are being followed up with the Health Service Executive and the Commission.

Feedback from local mental health services indicates that implementation of Part 2 is an additional challenge for existing services. A period of time is required for services to adapt to the significant changes to procedures brought about by the new Act. It is not possible to draw meaningful conclusions on trends in involuntary admissions at this early stage.

The review below considers the six main parts of the 2001 Act in turn. This is followed by a set of key findings and conclusions. 


\section{PART 1: PRELIMINARY AND GENERAL}

\section{INTERPRETATION (SECTION 2)}

Submissions received contain a number of suggestions in relation to definitions. These are outlined in the following paragraphs:-

"Consultant psychiatrist": should include specialist registrars acting on the authorisation of consultant psychiatrist trainers and that a senior registrar substituting for his or her educational supervisor be allowed to sign admission and renewal orders. The Minister has considered these suggestions. At this early stage of operation of the Act, he considers that it is not desirable to change the definition, which could potentially lessen the protection afforded to the patient. Amending the definition may also have unintended implications for the role of the consultant psychiatrist under the Mental Health Act 2001 and other consultants in the wider health area.

"Registered medical practitioner": Clarification was requested on the capacity to practice of those temporarily registered. The general register of medical practitioners maintained by the Medical Council contains three types of registration: full registration, internship registration and temporary registration. All names on the general register are considered "registered medical practitioner" for the purposes of the Act.

"Functional area": Submissions queried the definition of "functional area" and how this applies to homeless people. The Minister points out that this definition no longer applies because of the single unitary structure of the health service since the Health Act 2004. The issue of catchment areas and homeless persons is an operational matter to be addressed by the HSE.

"Tribunal": A number of comments were received in relation to the term "tribunal", suggesting that the term now had a negative perception. The term "mental health review panel" has been proposed. The Minister is of the view that the use and positive repute of the term "Mental Health Tribunal" in the mental health context can only be established over time. 


\section{MENTAL DISORDER (SECTION 3)}

Section three of the Act sets out the criteria for mental disorder as being 3(1)(a) or $3(1)(b)$.

3.-(1) In this Act "mental disorder" means mental illness, severe dementia or significant intellectual disability where-

(a) because of the illness, disability or dementia, there is a serious likelihood of the person concerned causing immediate and serious harm to himself or herself or to other persons, or

(b) (i) because of the severity of the illness, disability or dementia, the judgment of the person concerned is so impaired that failure to admit the person to an approved centre would be likely to lead to a serious deterioration in his or her condition or would prevent the administration of appropriate treatment that could be given only by such admission, and

(ii) the reception, detention and treatment of the person concerned in an approved centre would be likely to benefit or alleviate the condition of that person to a material extent.

In the Judgement delivered by Mr Justice O'Neill in the case of M.R. ${ }^{1}$, the court found that sections 3(1)(a) and 3(1)(b) "are not alternative to each other" ${ }^{2}$ and ruled that "the compulsion of an alternative choice between s. 3(1)(a) and s. 3(1)(b) is incorrect..."3. The Court further ruled that the Mental Health Commission Form 7 "should be amended so as to allow in appropriate cases for the selection of both provisions... by changing the "OR" to "AND/OR", in between the two provisions as set out on the form." 4 The Minister is satisfied that the Judgement does not mandate an amendment to the Act, however, he will consider whether an amendment is desirable in the interest of clarity.

The Judgement of Mr Justice O'Neill in that case also provides guidance on the interpretation of the terms "serious likelihood", "immediate" and "serious harm".

\footnotetext{
${ }^{1}$ M.R. v. Sligo Mental Health Services (High Court, O’Neill J., unrep., 2 March 2007)

${ }^{2}$ at page 15 of the Judgement

${ }^{3}$ at page 30 of the Judgement

${ }^{4}$ at page 30 of the Judgement
} 
The Act defines "mental illness", "severe dementia" and "significant intellectual disability" as follows:

(2) In subsection (1)-

"mental illness" means a state of mind of a person which affects the person's thinking, perceiving, emotion or judgment and which seriously impairs the mental function of the person to the extent that he or she requires care or medical treatment in his or her own interest or in the interest of other persons;

"severe dementia" means a deterioration of the brain of a person which significantly impairs the intellectual function of the person thereby affecting thought, comprehension and memory and which includes severe psychiatric or behavioural symptoms such as physical aggression;

"significant intellectual disability" means a state of arrested or incomplete development of mind of a person which includes significant impairment of intelligence and social functioning and abnormally aggressive or seriously irresponsible conduct on the part of the person.

The Act ensures that intellectual disability and severe dementia alone are not grounds for detention. The Act also explicitly excludes personality disorder, social deviance and addiction from the criteria for involuntary detention.

Different positions emerged from submissions in relation to the definitions of "severe dementia" and "significant intellectual disability" which proposed both the exclusion and retention of references to physical aggression in the definition. The Minister has considered these opinions and does not propose to amend the definitions at this early stage of the operation of the Act.

\section{CAPACITY}

A number of submissions received raised the issue of capacity, both in terms of capacity to consent to voluntary admission and capacity to consent to treatment. Some people do not have the capacity to consent to voluntary admission but do not 
fulfil the criteria for involuntary admission under the Act. The Law Reform Commission has recommended the enactment of capacity legislation. The Minister considers that the enactment of such legislation would be helpful for the treatment and care of people with mental illness, dementia and intellectual disabilities.

\section{BEST INTERESTS OF THE PERSON (SECTION 4)}

Clarification has been sought on the definition of "best interest". Section 4 states that the best interests of a person should be the paramount consideration in making decisions under the Act. The Minister considers that this is a difficult concept to define in legislation, although some guidance may be provided in future court judgements. 


\section{PART 2: INVOLUNTARY ADMISSION OF PERSONS TO APPROVED CENTRES}

Under the Mental Treatment Act 1945, a person entering a psychiatric hospital or psychiatric unit was admitted either as a voluntary patient, a temporary patient or a person of unsound mind. The procedures for admission and discharge varied for each category of patient. Our obligations under the European Convention required a redefinition of the criteria for the detention of people suffering from a mental disorder, the introduction of an independent process to review involuntary admissions and safeguards for detained patients.

Part 2 of the Mental Health Act 2001 outlines the procedures for involuntary admission to approved centres and the rights available to patients following admission, including right of review and right of appeal. Procedures regarding the transfer of patients and the discharge of patients are also outlined and the powers of the Garda Síochána are specified.

The 1945 Act provided, in the case of a temporary patient, for an initial period of detention of six months and in the case of a person of unsound mind for an undefined period of detention. The 2001 Act abolished this distinction and limits the initial period of detention to 21 days. The detention period may be extended by a period of three months, six months and twelve months if necessary. All admission and renewal orders are subject to automatic review by a Mental Health Tribunal.

The provisions of Part 2 of the Act commenced on the 1 November 2006. At midnight on the 31 October there were 388 patients involuntarily detained under the Mental Treatment Act 1945. In the first four months since the 1 November 2006, there were 451 involuntary admissions to approved centres and 205 involuntary admissions from within approved centres (detailed statistics are provided in Appendix 3). In 2005 there was a total of 2,830 involuntary admissions. Statistics in relation to involuntary admissions are updated on a monthly basis on the Mental Health Commission's website (www.mhcirl.ie).

\section{AUTHORISED OFFICERS (SECTION 9)}

Under the Mental Health Act 2001 (Authorised Officer) Regulations 2006 (S.I. No 550 of 2006), Local Health Managers, General Managers, Grade VIII staff, Psychiatric 
Nurses, Occupational Therapists, Psychologists and Social Workers may be authorised by the Chief Executive of the HSE to exercise the powers conferred on authorised officers by section 9 of the Act, i.e. they may make an application to a registered medical practitioner for a recommendation for the involuntary admission of a person to an approved centre.

The Act prohibits a member of staff from the approved centre concerned from making an application for involuntary admission. This is to ensure no possible conflict of interest in making an application for a person to be involuntarily admitted. Some submissions suggest that this provision is creating a difficulty in relation to the operation of the authorised officer system. The difficulty arises in the interpretation of "staff of the approved centre". In many mental health services there is not a clear demarcation between staff of the approved centre and staff of community mental health services. In some locations, community mental health staff may be based in an approved centre. In cases of possible conflicts of interest, the HSE is using staff from neighbouring areas to act as authorised officers.

Currently the HSE has 80 authorised officers who have been provided with training. In the first four months of the full operation of the Mental Health Act 2001, 21 applications for involuntary admission were made by authorised officers. This represents approximately $4.6 \%$ of involuntary admissions.

Concern has been expressed in submissions about the availability of authorised officers outside of normal office hours. The HSE is working to develop a comprehensive authorised officer service and that alternatives to involuntary admission are actively considered by authorised officers.

The Minister is satisfied that the issues raised in relation to authorised officers are being addressed by the HSE.

\section{REGISTERED MEDICAL PRACTITIONERS (SECTION 10)}

Section 10(2) requires the examination of the person by a registered medical practitioner to be carried out within 24 hours of the receipt of the application. It has been suggested that 24 hours before or after the receipt of the application may be more appropriate. Having considered the matter, the Minister does not feel it is appropriate to amend the Act as to do so could lessen the protection for the person. 


\section{GARDA SÍOCHÁNA (SECTIONS 9, 12 AND 13)}

Members of the Garda Síochána have a number of powers under the Act. These include:

- $\quad$ making an application for involuntary admission under section 9(1)(c);

- taking a person into custody if there are reasonable grounds for believing that a person is suffering from a mental disorder and may cause immediate and serious harm to himself or herself or to others under section 12(1)(a);

- making an application to a registered medical practitioner for a recommendation for involuntary admission under section 12(2);

- $\quad$ bringing the person to the approved centre under section 12(5);

- assisting in the removal of a person to an approved centre if requested by the clinical director of an approved centre under section13(3).

In the first four months of the operation of Part 2 of the Act, 63 involuntary admissions occurred following applications by members of the Garda Síochána. This represented approximately $14 \%$ of involuntary admissions during this period.

Section 12(1)(b) allows a member of the Garda Síochána to enter any premises by force if there are reasonable grounds for believing that a person is suffering from a mental disorder and may cause immediate and serious harm to himself or herself or to others. Some submissions suggest that a warrant from the District Court should be required in such circumstances. It is, however, the Minister's view that the Act is clear on this matter and no change is proposed.

Section 12(4) requires the Garda Síochána to release a person from custody immediately if a registered medical practitioner refuses an application for involuntary admission. It is the Minister's view that this provision does not conflict with the separate powers of members of the Garda Síochána to arrest or detain a person pursuant to their powers under criminal law.

\section{REMOVAL OF PERSONS TO AN APPROVED CENTRE (SECTION 13)}

Section 13 of the Act sets out the procedures for the removal of a person to an approved centre. When a person with a mental disorder requires admission to an approved centre but is not willing to go voluntarily, an assisted admission is required.

Section 13 of the Mental Health Act 2001 places the primary responsibility for the provision of assisted admissions on the clinical director of the approved centre. If 
necessary, the clinical director may call on the Garda Síochána to assist the staff of the approved centre in the assisted admission.

Clarification has been requested about:

- Holding people in A\&E departments, i.e. a place other than an approved centre, prior to the arrival of assisted admission teams. The Minister considers that the HSE and hospital management should ensure that there is no delay in the admission of a person to an approved centre in these circumstances.

- The roles and responsibilities of members of the Garda Síochána and staff of the approved centres. It is the Minister's view that training for Gardaí in relation to these functions is a matter for the Garda authorities and notes that section 13 of the Act states that the Garda Síochána shall assist with the removal of a person to an approved centre if requested to do so by the clinical director or a consultant psychiatrist acting on his or her behalf.

- When is an involuntary admission considered to have occurred? Detention/involuntary admission is considered to have occurred when the consultant psychiatrist signs the admission order.

Some submissions reported difficulties with the assisted admissions process. The HSE has contracted an outside agency to provide the assisted admissions service. This service should be evaluated and difficulties identified addressed by the HSE.

\section{PROVISION OF INFORMATION FOR PERSONS ADMITTED TO APPROVED CENTRES (SECTION 16)}

Persons involuntarily admitted to an approved centre must be provided with written notice of their admission or renewal order. This notice must include a statement that the patient may be admitted as a voluntary patient if he or she wishes (section 16(2)(g)). This option is considered by some medical practitioners to be confusing for patients and may not be desirable for someone who fulfils the criteria for a mental disorder. However, the Minister considers that it is not appropriate to take this discretion away from service users as provided for in the Act. 
Submissions have also suggested that patients be provided with the substantive reasons for their detention when the admission order is made. The Regulations for Approved Centres (S.I. No. 551 of 2006) require patients to be provided with information about their diagnosis. The Minister does not consider any changes to the Act necessary in this regard. He notes that section 56 of the Act also requires the consultant to give the patient adequate information on the nature, purpose and likely effects of proposed treatment.

\section{REFERRAL OF ADMISSION AND RENEWAL ORDERS TO MENTAL HEALTH TRIBUNALS (SECTION 17)}

Section 17 currently states:

"Following the receipt by the Commission of a copy of an admission order or a renewal order, the Commission shall, as soon as possible-

(a) refer the matter to a tribunal..."

It has been suggested that section 17 of the Act should be amended to read:

"Following the receipt by the Commission of a copy of an admission order or a renewal order, the Commission shall, arrange for the following to be done as it deems appropriate to ensure that the review by a tribunal is completed within the required time period -

(a) appoint a tribunal..."

Due to the high proportion of admission orders that are revoked prior to the holding of a Mental Health Tribunal within 21 days, the Mental Health Commission considers that it is not cost effective to refer the matter to a Mental Health Tribunal "as soon as possible". Fees are payable, to Mental Health Tribunal members, legal representatives and consultants providing second opinions, when a planned hearing is cancelled due to the revocation of an admission order by the consultant psychiatrist.

The Minister believes that the interests of patients detained under this Act are paramount. In many instances the acute phase of the illness will be short and revocation of the admission order is appropriate. He is concerned, however, about the high level of revoked admission orders that do not progress to a Mental Health Tribunal. He is also concerned about the disruption to services which can arise from the late notification of Mental Health Tribunal hearings. The Minister considers that Mental Health Tribunal hearings should take place 
at the earliest possible opportunity and that all necessary arrangements should be made to facilitate this.

The Minister would suggest that provision of a Mental Health Tribunal hearing as soon as possible after an involuntary admission is made will reduce the number of admission orders that are revoked prior to the tribunal hearing, facilitate better spacing of any second Mental Health Tribunal, alleviate difficulties experienced by both patients and service providers and minimise disruption to services. The Mental Health Commission and service providers should work together, on an ongoing basis, to ensure optimal collaboration in relation to the Mental Health Tribunal process.

Second opinion examination for the tribunal - The Minister is of the view that the 14 day time period allowed for in section $17(1)(c)(i i i)$ to receive the second consultant's report should be reduced. The planned increase in consultant numbers should facilitate this. This would enable the earlier scheduling of Mental Health Tribunals and provide earlier access by patients and their legal advisors to the second opinion reports prior to hearings.

\section{REVIEW BY A MENTAL HEALTH TRIBUNAL OF ADMISSION AND RENEWAL ORDERS (SECTION 18)}

Some submissions suggest that the integration of the independent review of detention into the day to day operation of the HSE mental health services is creating a number of difficulties affecting patient welfare, patient care, and the capacity of mental health services to deliver care and treatment in the most effective and efficient manner consistent with the best interests of the patient. Submissions also suggested that the 21 day timeframe for the reviewing of renewal orders is creating operational difficulties. A patient admitted will have their admission order (which is valid for 21 days) reviewed by a Mental Health Tribunal within 21 days. If the patient is then the subject of a renewal order (valid for three months), a second Mental Health Tribunal must take place within 21 days of the renewal order being made.

The Judgement of Mr Justice Peart ${ }^{5}$ ruled that the Mental Health Tribunal must take place within 21 days of a renewal order being signed and not 21 days after the expiration of the admission or previous renewal order.

\footnotetext{
${ }^{5}$ AMC v. St Luke’s Hospital, Clonmel (High Court, Peart J., unrep., 28 February 2007)
} 
It has been suggested that that Act should be amended so that a renewal order only becomes effective after the expiry of the admission order or previous renewal order. The Minister has considered this suggestion in the context of the operational difficulties that have arisen to date. However, the Minister does not believe an amendment is desirable. The intention of the Act is clear and Mental Health Tribunals must be held within 21 days of the renewal order being made. The Commission may wish to issue guidelines advising consultant psychiatrists that a Mental Health Tribunal must be held within 21 days of making a renewal order and that any renewal order should not ideally be made until the date of expiry of the existing order. It should also be noted that section 18(4) allows the Mental Health Tribunal to postpone the Mental Health Tribunal hearing by a period of 14 days.

Some submissions suggest that the first Mental Health Tribunal should be held within 10 days of admission, as many patients will have improved before the expiry of the full 21 day period.

It has been suggested that the timing of the second Mental Health Tribunal is placing pressure on all parties, including patients. Suggestions received for addressing these concerns include:

- Extending the timescale of the admission order to 42 days, whilst retaining the 21 day time period for the Mental Health Tribunal hearing to take place, or;

- Changing the timeframe for the Mental Health Tribunal hearing on a renewal order to 42 days, or;

- Providing for a 30/35 day time-frame in which the review of a renewal order must occur.

Some submissions suggested that such changes would not significantly undermine the protections afforded to the person and could reduce the distress that can be associated with the anticipation and experience of Mental Health Tribunal hearings. The changes, it is argued, would also provide a more realistic and manageable timeframe for service providers and the Mental Health Commission to deliver on the review requirements.

Mental Health Tribunals have only been in operation since November 2006. They represent one of the most radical features of the legislation. As indicated 
earlier, the Minister believes that they should be provided as soon as possible after involuntary admission. The Minister acknowledges the tight timeframes involved but is reluctant to dilute the protections afforded to patients. This part of the Act will be considered further by the Mental Health Commission under section 42(4) by the end of April 2008. The Minister considers that the matter can be revisited when that report is available (see also Part 3).

\section{CIRCUIT COURT APPEALS (SECTION 19)}

All persons who have their admission or renewal order affirmed by a Mental Health Tribunal are entitled, under section 19, to appeal the decision to the Circuit Court on the grounds that they are not suffering from a mental disorder. The onus is on the patient to show that he or she is not suffering from a mental disorder. In the first four months of the operation of Part 2 of the Act, eight decisions were appealed to the Circuit Court under section 19.

It has been suggested in some submissions that there should be greater parity between the two parties. It is suggested that the onus of proof should be on the detainer rather than the patient to ensure full compliance with the European Convention on Human Rights.

The Minister points out that this matter was considered prior to the enactment of the legislation. The Act is premised on the principle that the decision as to mental disorder is a medical one. It is, therefore, the Mental Health Tribunal which has the function of review and appeal of the decision. An appeal to the Circuit Court is not a full appeal in the ordinary sense but, rather, a new statutory mechanism to challenge the substance of the decision of the Mental Health Tribunal. Legal advice received is that the correct balance in this additional appeal mechanism is provided for in the Act: it gives the individual the means to overturn a decision while at the same time giving due weight to the decision of the Mental Health Tribunal.

This appeal mechanism is in addition to the habeus corpus provisions in the Constitution (Article 40(4)).

\section{TRANSFER OF PATIENTS (SECTION 20 AND 21)}

The Act outlines the procedure that must be followed for the transfer of a patient from one approved centre to another (other than the Central Mental Hospital). Section 20 
(1) of the Act requires the consent of the clinical director of the receiving centre before a transfer may be made.

Submissions received have requested guidance on the role and responsibilities of the consultant psychiatrists in both centres. Clarification has been requested as to who is responsible for renewal orders, attendance before a Mental Health Tribunal, etc. The Act is clear that the detention of a person in another approved centre is deemed to be detention in the centre from which he or she was transferred. The Minister is of the view that guidance should be provided by the Mental Health Commission on this matter following consultation with his Department, the HSE and relevant stakeholders.

Submissions also requested that guidance be provided on the information that must be forwarded to the receiving centre. The requirements for the provision of information to receiving centres are outlined in the Regulations for Approved Centres (S.I. No. 551 of 2006).

The Act sets out the procedure for the transfer of a patient to the Central Mental Hospital. The Act does not require the consent of the clinical director of the Central Mental Hospital for the transfer of a patient to that hospital. Submissions suggested that the advice of the clinical director of the Central Mental Hospital be sought prior to submitting a proposal to the Mental Health Commission for the transfer of a patient to the Central Mental Hospital.

The Minister points out that transfers to the Central Mental Hospital are through the Mental Health Tribunal process. Therefore, to require the consent of the clinical director of the Central Mental Hospital could theoretically result in an opposite view. The Minister is of the opinion that the Mental Health Tribunal may consult with the clinical director of the Central Mental Hospital in the course of reviewing the proposal to transfer a patient to the Central Mental Hospital.

The transfer to the Central Mental Hospital cannot take place until (a) a Mental Health Tribunal has determined that such a transfer would be in the best interest of the health of the patient concerned and (b) until the period of time for the bringing of an appeal to the Circuit Court has expired. If an appeal is made the transfer cannot take place until after the appeal is either determined or withdrawn. 
The time period required by the Act before a patient may be transferred to the Central Mental Hospital is causing difficulties in the approved centres. These approved centres may not have suitable facilities for the detention of a patient who requires treatment in the Central Mental Hospital pending his or her transfer. The Minister appreciates the difficulties that are being experienced by local services but considers that these will be alleviated by the development of intensive care rehabilitation units.

An issue also arises when patients in the Central Mental Hospital detained under the Criminal Law (Insanity) Act 2001 reach the end of their sentence but continue to require treatment in the Central Mental Hospital due to their mental disorder. Currently, such patients are transferred to local mental health services, detained under the Mental Health Act 2001 and an application for transfer to the Central Mental Hospital is considered by a Mental Health Tribunal. Some submissions have suggested that the Act be amended to allow such patients to remain in the Central Mental Hospital. The Minister considers that this issue can be addressed by the provision of intensive care rehabilitation units as recommended in "A Vision for Change". The Minister is of the view that the development of these units must be prioritised by the HSE. The Minister will keep this issue under review.

The Act also provides for the transfer of a patient to a hospital for treatment. It has been suggested that the timeframe for the Mental Health Tribunal hearing, i.e. 21 days, should exclude any time spent in hospital. The Minister does not agree with this proposal. The Act clearly states that the detention of a person in a hospital shall be deemed to be detention for the purposes of the Act.

\section{POWERS TO PREVENT VOLUNTARY PATIENTS FROM LEAVING AND TO DETAIN VOLUNTARY PATIENTS (SECTIONS 23 AND 24)}

Section 23 of the Act allows for the detention of a voluntary patient for up to 24 hours, where he or she has indicated a wish to leave the approved centre and is believed to be suffering from a mental disorder. The process for making an involuntary admission order for a person detained under section 23 is outlined in section 24 .

Submissions suggested that the requirement for a person to indicate that he or she wishes to leave is too restrictive and that the consultant psychiatrist should be permitted to detain the person if the criteria for a mental disorder are met. A voluntary patient whose condition deteriorates to the extent that he or she would meet the 
criteria for a mental disorder cannot have their status changed unless they indicate a wish to leave the approved centre.

Some submissions have suggested the removal of the reference to section 23 in section 24. Another suggestion was to amend section 23 so that the grounds on which the person can be re-graded are not specified except for meeting the criteria for a mental disorder. Submissions have also suggested that the 24 hour timeframe provided for in section 23(1) should be extended to 48 hours to allow the same detention procedures as for people from outside an approved centre, i.e. under sections 9 and 10 .

Having considered the matter carefully, the Minister has a strong preference for the use of the normal involuntary admission procedures when a voluntary patient has a mental disorder and requires involuntary admission for treatment. The Minister wishes to ensure that the status of patients should not lightly be changed from voluntary to involuntary, and that the rights of patients in this regard are fully safeguarded. The legal scope for using the normal admission procedures under sections 9 and 10 will be examined.

\section{INVOLUNTARY ADMISSION OF CHILDREN (SECTION 25)}

The treatment of children and adolescents with mental health problems takes place mainly in primary care settings and community mental health services. The vast majority of admissions of children to approved centres are initiated by the child's parent(s) or guardian(s). The Act provides, in exceptional circumstances, for the involuntary admission of children.

To ensure consistency with other legislation the Mental Health Act 2001 defines a child as a person under 18 unless he or she is or has been married. The Mental Treatment Act 1945 defined a child as a person under 16 years of age.

If a child is suffering from a mental disorder and requires treatment which he or she is unlikely to receive unless an order is made, the HSE may make an application under section 25 to the District Court for an order authorising the admission and detention for treatment of the child in an approved centre, (whether that centre is operated by the HSE or other service provider). 
Court rules ${ }^{6}$ were introduced in March 2007 to provide procedures and forms in respect of applications under section 25 of the Act.

Four children were admitted under section 25 between November 2006 and February 2007 , out of a total of 49 child admissions to approved centres. Of the 49 children admitted to approved centres, over $80 \%$ were aged 16 or 17.

Concern was expressed in some submissions that the detention of a child under section 25 and any extension of the period of detention is not subject to a review by a Mental Health Tribunal. However, both the detention under section 25 and the extension of the period of the detention require an order of the District Court. In addition, the provisions of sections $21,22,24$ to 35,37 and 47 of the Child Care Act 1991, which includes the appointment of a Guardian ad litem if required, apply to proceedings under section 25 . The Minister is of the view that the protections provided for in legislation ensure that the child's best interests are protected.

A number of comments made in the submissions relating to the involuntary admission of children highlight the need for a good working relationship between child and adolescent mental health services and child care and protection services. For example, some involuntary admissions of children could arise from section 12 of the Child Care Act 1991 (Power of An Garda Síochána to take a child to safety). The Minister believes the HSE should develop a protocol regarding the roles and responsibilities of staff involved in the admission of children under section 25 of the Act.

Concern has also been expressed in submissions that the Act contains no provision for the views of the child to be taken into consideration. The Minister points out that section 24 of the Child Care Act 1991, which applies to proceedings under section 25 of the Mental Health Act 2001, states that in so far as is practicable, proceedings before a court shall give due consideration to the wishes of the child having regard to his/her age and understanding.

\footnotetext{
${ }^{6}$ District Court (Mental Health) Rules 2007 (S.I. No. 97 of 2007)
} 
Some submissions have suggested that the 21 day detention period for a child may be considered excessive. The Minister notes that the District Court has discretion to make an order for a lesser period.

\section{ABSENCE WITH LEAVE (SECTION 26)}

It has been suggested that the requirement to direct a patient in writing to return to the approved centre is unworkable as the clinical director may not have the current address for the patient. In this regard, the Minister is of the view that the consultant psychiatrist would be expected to satisfy himself or herself, prior to granting absence with leave, as to where the patient will reside and how the patient can be contacted.

\section{ABSENCE WITHOUT LEAVE (SECTION 27)}

Clarification has been requested as to the time and geographical criteria for defining absence without leave. The Minister does not consider this a matter appropriate to legislation. Responses to absences without leave will vary and must take into account the individual circumstances of each instance. The Minister considers that it would be helpful for the HSE and the Mental Health Commission to develop guidance on this matter.

\section{DISCHARGE OF PATIENTS (SECTION 28)}

If a treating consultant psychiatrist is of the opinion that the patient is no longer suffering from a mental disorder he or she may revoke the admission or renewal order, but at the person's request a Mental Health Tribunal may still be held to review his or her involuntary admission.

Some submissions suggest that the role of a Mental Health Tribunal in this instance is unclear. The Mental Health Tribunal in accordance with sections 17 to 19 must decide whether the patient is suffering from a mental disorder. However, if the patient has been discharged, the consultant psychiatrist has deemed that the patient is no longer suffering from a mental disorder and, therefore, the Mental Health Tribunal will not have any order to affirm or revoke.

The provisions of sections 17 to 19 apply to a review carried out under section 28 with any necessary modifications. The Minister considers that the intention for the Mental Health Tribunal in this instance is to review the detention of the patient concerned to satisfy itself, insofar as is possible, that the patient was 
suffering from a mental disorder when the admission order or renewal order was made. The Mental Health Tribunal must also satisfy itself that the correct procedure for involuntary admission was complied with and that the patient was not unjustly detained.

It is of course appropriate that admission orders are revoked when the patent is no longer suffering from a mental disorder. The Minister is, however, concerned at the high level of admission orders revoked prior to a Mental Health Tribunal and which do not result in a tribunal hearing. In the first four months of the operation of Part 2 a total of 505 admission orders were revoked by the responsible consultant psychiatrist before the Mental Health Tribunal was held. He considers that if Mental Health Tribunal hearings were held at an earlier stage in the $\mathbf{2 1}$ day period the number of orders revoked before the hearing occurs would be likely to fall. 


\section{PART 3: INDEPENDENT REVIEW OF DETENTION}

Part 3 of the Act outlines the functions and powers of the Mental Health Commission and Mental Health Tribunals. The establishment of the Inspector of Mental Health Services and related functions are also outlined.

The Mental Treatment Act 1945 assigned significant powers to the Inspector of Mental Hospitals to protect patients in psychiatric hospitals. The Inspector visited and inspected every health board psychiatric hospital or unit once per year and every registered private psychiatric hospital and the Central Mental Hospital twice yearly. The 2001 Act replaces the Inspector of Mental Hospitals with the Inspector of Mental Health Services.

\section{MENTAL HEALTH COMMISSION (SECTION 33)}

The main vehicle for the implementation of the provisions of the Mental Health Act, 2001 is the Mental Health Commission. The Commission was established in April 2002. An independent statutory body, its primary function is to promote and foster high standards and good practices in the delivery of mental health services and to ensure that the interests of detained persons are protected.

\section{MEMBERSHIP OF MENTAL HEALTH COMMISSION (SECTION 35)}

It has been acknowledged that occupational therapists play a key role in the delivery of our mental health services. Currently, the Mental Health Act 2001 does not provide for the appointment of an occupational therapist to the Mental Health Commission. The Minister considers that any future amendments to the Act should provide for the appointment of a representative of occupational therapists.

Some submissions have suggested that the appointment of two consultant psychiatrists to the Mental Health Commission is not sufficient to reflect the range of specialist expertise and experience. The Commission may make arrangements to access relevant specialist expertise as required for committees, subgroups, etc. In the interests of effective and efficient working, the Minister would not be in favour of the appointment of a larger Commission to reflect the range of medical specialists in mental health. 
REVIEW OF ADMISSION/RENEWAL ORDERS BY A MENTAL HEALTH TRIBUNAL (SECTIONS 48 AND 49)

In the first four months of operation a total of 556 Mental Health Tribunals were held. Submissions suggest that a system of reporting of Mental Health Tribunal decisions would be a useful measure to ensure transparency and consistency in the Mental Health Tribunal process. The Minister notes that the Mental Health Commission publishes updated monthly activity statistics relating to involuntary admissions and Mental Health Tribunals on its website (www.mhcirl.ie).

A number of submissions received refer to difficulties in the operation of Mental Health Tribunals in approved centres. Some of the difficulties mentioned included scheduling of Mental Health Tribunals; claims of an adversarial approach by some legal representatives; disruptions caused by visits to centres by legal representatives and second opinion consultants; access to independent second opinion assessment reports prior to the Mental Health Tribunal occurring; and uncertainty over who is responsible for sending forms to the Commission.

The Commission has conducted additional chairperson training and will continue to provide training as required. It is acknowledged that the introduction of Mental Health Tribunals represents a significant change for both service users and service providers. Since January 2007, 5-6 days notice is given for Mental Health Tribunals. Because of the high level of revocation of orders it is in the practice of the Mental Health Commission to establish Tribunals later in the 21 day period to minimise costs i.e. payment to tribunal members. However, this approach can be disruptive to service provision and only permits minimum notice of hearings to approved centres.

As stated earlier, the Minister is of the view that Mental Health Tribunals should be arranged at the earliest possible time following a person's involuntary admission to a centre. This would facilitate more notice to centres and minimise disruption to existing services. The earlier scheduling of hearings will minimise the number of admission orders that are revoked prior to the Mental Health Tribunal hearing.

The Minister considers that issues relating to access by patients to their legal representative should be addressed by the Mental Health Commission. 
It is suggested in submissions that the procedures for informing patients and service providers of Mental Health Tribunal decisions are unclear. The Minister is of the view that the Mental Health Commission should consider if there is a need to develop guidance on this issue.

\section{INSPECTOR OF MENTAL HEALTH SERVICES (SECTIONS 50 - 54)}

The Commission appointed the first Inspector of Mental Health Services in September 2003. The Inspector of Mental Health Services and the assistant inspectors use the collective title the Inspectorate of Mental Health Services. The Inspectorate consists of the Inspector and a team of six Assistant Inspectors which was appointed in 2004 comprising one full-time nurse, two part-time consultant psychiatrists, one part time occupational therapist, one part-time social worker and one part-time clinical psychologist.

Some submissions received questioned the appropriateness of a non-psychiatrist assistant inspector examining and commenting on medical matters. Other submissions emphasised the need for inspection teams to comprise a number of disciplines. The Minister's view is that a multidisciplinary service should be inspected by a multidisciplinary inspectorate.

The work of the Inspector is generally viewed positively by stakeholders in submissions received. It is systematic and thorough and provides valuable information on the provision of services to clients. The practice of highlighting good models of service delivery is particularly welcomed. Some service providers have indicated that increased access to guidance and support from the inspectorate would be useful.

As suggested in some submissions, the Minister considers that formal links should be established between the Mental Health Commission and the Health Information and Quality Authority to facilitate the sharing and promulgation of best practice throughout health and personal social services. Formal links are also required to ensure that services are inspected by the appropriate inspectorate. 


\section{PART 4: CONSENT TO TREATMENT}

Part 4 of the Mental Health Act 2001 outlines the requirements for consent to treatment by patients and the circumstances where second opinions, or review by a Mental Health Tribunal are required i.e. electro-convulsive therapy, the administration of medicine and psycho-surgery.

The Mental Treatment Act 1945, and subsequent amending legislation, did not address the issue of informed consent to treatment of a detained patient.

For the purposes of Mental Health Act 2001, consent means consent, obtained freely without threats or inducements, where

- the consultant psychiatrist responsible for the care and treatment of the patient certifies that the patient is capable of understanding the nature, purpose and likely effects of the proposed treatment, and

- the psychiatrist has given the patient adequate information, in a form and a language that the patient can understand on the nature, purpose and likely effects of the proposed treatment.

Under the Mental Health Act 2001, the consent of a patient to treatment is required except where the consultant psychiatrist considers that the treatment is necessary to safeguard the life of the patient, to restore his or her health, to alleviate his or her condition, or to relieve his or her suffering, and the patient is incapable of giving such consent because of his/her mental disorder. The Minister is of the view that the provisions relating to consent to treatment will require further consideration in the context of any new capacity legislation.

There have been some suggestions that the side effects of medicines are not explained to patients. The Minister points out that this is provided for in section 56 and has also been addressed in the Regulations for Approved Centres. The Regulations require that information is provided to each resident in an understandable form and language on indications for use of all medications to be administered to the resident, including any possible sideeffects. 


\section{ELECTRO-CONVULSIVE THERAPY (ECT) (SECTION 59)}

A programme of electro-convulsive therapy may not be performed unless the patient gives consent or, where the patient is unable or unwilling to give consent, the therapy is authorised by the consultant psychiatrist responsible for the patient and by another consultant psychiatrist. The Mental Health Commission has published rules providing for the use of electro-convulsive therapy under section 59(2). These rules will be kept under periodic review by the Mental Health Commission, and revised as required. Submissions suggested that the Act be amended so that these rules also apply to voluntary patients. The Minister considers that it would not be appropriate to amend the legislation for this purpose. However, it is the Minister's view that the rules should also guide the administration of electro-convulsive therapy to voluntary patients.

Some submissions have suggested that only a Mental Health Tribunal should be empowered to authorise electro-convulsive therapy. The Minister is of the view that the 2001 Act represents a significant advancement on the Mental Treatment Act 1945. Part 4 of the 2001 Act is only in operation since November 2006. Any review of the rules governing the use of electro-convulsive therapy undertaken by the Mental Health Commission should ensure that international best practice continues to be taken into account.

Submissions also sought clarification on the appropriate procedure for when a patient, who has given written consent, changes his or her mind. The Minister points out that this eventuality is provided for in the Mental Health Commission's rules governing the use of electro-convulsive therapy.

Submissions suggest that the reference to "unwilling" be deleted from this section. Where capacity exists any refusal to accept treatment should be respected and this right protected by law. The Minister accepts in principle this suggestion but would wish to consider the implications in the context of any new capacity legislation.

\section{ADMINISTRATION OF MEDICINE (SECTION 60)}

Where the patient is receiving medicine for the amelioration of a mental disorder for a period of three months, the medicine must be discontinued unless the patient consents or, where the patient is unable or unwilling to give consent, the continued 
medication is authorised by the consultant psychiatrist responsible for the patient and by another consultant psychiatrist.

Again, submissions recommend that the reference to "unwilling" be deleted from this section. Where capacity exists any refusal to accept treatment should be respected and this right protected by law. The Minister accepts the principle and is of the view that this requires to be considered in the context of any new capacity legislation.

It has also been suggested that nursing staff should be consulted regarding the administration of medicine both initially and following the three month period. It is the Minister's view that the multidisciplinary nature of modern care and treatment will provide for such inputs.

Concerns have been expressed that this section poses a significant workload in relation to patients without capacity and for whom this was not going to change (e.g. patients with severe dementia) and who had a long-term requirement for medication. The independent assessment can also be a source of distress to patients, because of the nature of their condition. The Minister is of the view that it is too early to assess the impact of this provision. The Minister is also of the view that this provision is a significant safeguard for patients.

\section{TREATMENT OF CHILDREN (SECTION 61)}

Section 61 provides for the review of the administration of medication to a child in respect of whom an order under section 25 is in force. Whilst section 61 is similar to section 60 , the process for the detention of a child under section 25 is quite different to the involuntary admission of an adult and this is not correctly reflected in section 61.

The Minister accepts that there appears to be a drafting error in this section which requires to be amended. This amendment will be made as soon as a suitable opportunity arises. 


\section{PART 5: APPROVED CENTRES}

Part 5 of the Mental Health Act 2001 replaces the provisions of the Mental Treatment Act 1945 for the registration of hospitals or other in-patient facilities for the care and treatment of people suffering from mental illness.

The Mental Health Commission is responsible for establishing and maintaining a register of approved centres operated by both the statutory and non-statutory service providers. Such centres are defined as hospitals or other in-patient facilities for the care and treatment of people suffering from mental illness or mental disorder.

For a centre to operate as an Approved Centre, it must make an application to the Mental Health Commission. The Commission can issue a Certificate of Registration with or without conditions, or revoke or amend a condition of registration. Registration is valid for three years provided the centre has not been removed from the register in the meantime. The registered proprietor of the centre must, two months prior to the expiry of the registration, apply to the Commission to have the centre re-registered. 58 centres have been registered by the Mental Health Commission to date (a list of approved centres is available on the Commission's website www.mhcirl.ie).

The Mental Health Commission has a statutory obligation to promote, encourage and foster the establishment and maintenance of high standards and good practices in the delivery of mental health services and to take all reasonable steps to protect the interests of persons detained in approved centres. In fulfilment of this obligation the Commission may attach any conditions it considers appropriate to the registration of approved centres.

The Approved Centre can appeal any decision by the Mental Health Commission to the District Court, within 21 days of the receipt of the notification from the Mental Health Commission. Under the Mental Health Act, 2001, fines and/or periods of imprisonment can be imposed on those guilty of offences.

Some submissions point out that there is a need to develop approved centres appropriate to the treatment of certain groups of people and suggest that there is a need to ensure that certain groups of people with mental illness, e.g. persons under 18 or people with an intellectual disability, are treated in specialist approved centres. The Minister's view is that this is a matter for the service providers and does not require an amendment to the Act. 
The name of the person who carries on the approved centre is entered on the Register of Approved Centres and he or she is known as the "registered proprietor". The registered proprietor of each centre has a number of obligations under both the Act and the regulations for approved centres. It has been suggested that the registered proprietor should be authorised to direct the Clinical Director and other members of the management of an approved centre as appropriate to adhere to regulations prescribed by the Minister and rules specified by the Mental Health Commission. The Minister has considered this proposal and believes that providing for such powers under the Act is unnecessary. It is the responsibility of all service providers to ensure that all members of staff of the approved centres are aware of and adhere to their obligations and responsibilities arising from the Act.

The Minister for Health and Children has made regulations on standards in Approved Centres, following consultation with the HSE and the Mental Health Commission. The purpose of these regulations is to ensure proper standards and conduct in relation to the operation of Approved Centres.

The regulations came into effect on the 1 November 2006. They were circulated to the HSE and all independent centres. The regulations are available on the Department of Health and Children's website (www.dohc.ie).

Submissions suggest that some existing centres are inadequate and unsuitable for the delivery of mental health services. Since the $1^{\text {st }}$ November 2006, the Mental Health Commission must ensure that all centres applying for registration comply with the regulations for approved centres. In addition it is the function of the Inspector of Mental Health Services to ascertain and report on compliance with regulations and rules. The Commission has also developed a quality framework for mental health services which sets out the standards expected of all services.

\section{CLOSURE OF AN APPROVED CENTRE}

Section 21 provides for the transfer of patients to other approved centres for the purpose of obtaining special treatment. Detention in another approved centre is deemed for the purpose of the Act to be detention in the centre from where he or she was transferred. 
There is, however, no provision in the Act dealing with the closure of approved centres and the issues arising e.g. the transfer of patients. The Minister is of the view that this should be provided for as soon as a suitable opportunity arises to amend the legislation. 


\section{PART 6: MISCELLANEOUS}

Part 6 outlines various miscellaneous provisions including restriction on bodily restraint and seclusion, participation in clinical trials, restriction on civil proceedings, provisions in relation to offences and the review of the 2001 Act.

\section{BODILY RESTRAINT AND SECLUSION (SECTION 69)}

The Mental Health Commission published rules providing for the use of seclusion and mechanical means of bodily restraint (S. 69(2)).

Submissions recommended that the reference to "voluntary patient" be deleted from this section. It is suggested that the use of "mechanical" restraint on voluntary patients may breach UN principles for the protection of persons with mental illness. The Minister points out that under the Act patients, both voluntary and involuntary, may not be restrained or placed in seclusion unless this is necessary for treatment or to prevent the patient from injuring him/herself. It is an offence to place a resident of an approved centre under mechanical bodily restraint or in seclusion otherwise than in accordance with the rules.

\section{CLINICAL DIRECTORS (SECTION 71)}

Every approved centre must appoint a consultant psychiatrist to be the clinical director of the centre. Submissions suggested that guidance is required on the duties and responsibilities of Clinical Directors. Submissions also suggested that Clinical Directors are required for each specialist area of psychiatry. The Minister is of the view that where issues arise regarding the duties and responsibilities of Clinical Directors, these should be addressed by the HSE with other service providers and take account of the changes currently taking place as a consequence of the implementation of 'A Vision for Change'.

\section{TRANSITIONAL PROVISIONS (SECTION 72)}

Section 72 contains a number of transitional provisions to facilitate the continued detention of persons under the 1945 Act. Under these provisions temporary patients were deemed to be detained for the unexpired period of their detention order and persons of unsound mind for a period not exceeding 6 months. 
Difficulties have arisen in the interpretation of some of the transitional provisions and have been the subject of a High Court judgment ${ }^{7}$. This judgement was essentially about the timing of the Mental Health Tribunal hearings. These transitional provisions will cease to apply from 1 May 2007.

A transitional period of three years from commencement of Part 2 (1 November 2006) is specified by section 72 (6) of the Mental Health Act 2001, during which hospitals or other inpatient facilities which immediately before commencement were providing care and treatment are deemed to be approved centres. This period may be reduced by the Minister. This provision is influenced by practical considerations, including the capacity of the Mental Health Commission to register approved centres. The Minister is anxious that a shorter time frame be prescribed as provided for in Section 72(b). The views of the Mental Health Commission on the period to be prescribed have been sought.

\section{LEAVE OF HIGH COURT FOR CERTAIN PROCEEDINGS (SECTION 73)}

The Act includes a provision which restricts the right of access to the courts arising from actions taken under the Act. This provides that, where something is done or purports to be done under the terms of the Act, a court action may not be taken in relation to it without the consent of the High Court. This consent will not be refused unless the High Court considers that the proceedings are frivolous or vexatious or that there are no reasonable grounds for arguing that the person against whom the proceedings are brought acted in bad faith or without reasonable care.

If the High Court allows the action to proceed, then the court cannot find in favour of the plaintiff unless it is satisfied that the defendant acted in bad faith or without reasonable care.

There have been a number of legal challenges to the Act since the 1 November 2006. Submissions suggested that clear guidance is required by service providers on any relevant rulings and challenges to the Act.

The Minister is of the view that it would be helpful if the Mental Health Commission were to publish relevant judgments relating to the Act on its website and issue advice to service providers as required. The Minister is also

\footnotetext{
${ }^{7}$ AMC v. St Luke's Hospital, Clonmel (High Court, Peart J., unrep., 28 February 2007)
} 
of the view that his Department should closely monitor legal developments which have implications for the Act. It would also be helpful if details of all legal challenges, hearings and court rulings were, as a matter of course, provided to his Department.

\section{REVIEW OF THE OPERATION OF THE ACT (SECTION 75)}

The Mental Health Act 2001 requires the Minister of Health and Children to review the Act not later than five years after establishment day (5 April 2002) and present a report to the Houses of the Oireachtas on the findings and conclusions of the review. Part 2, 4, 5 and 6 have only been in operation since the 1 November 2006. It is acknowledged that the time available did not allow for a comprehensive review. In many instances, it is too early to reach firm conclusions regarding the operation of the Act.

However it should also be noted that Section 42(4) requires the Mental Health Commission to prepare and submit a report to the Minister on the operation of Part 2 of the Act within 18 months of the commencement of that part, i.e. on or before the 30 April 2008. The Minister is of the view that the Mental Health Commission should consult with the principal stakeholders in preparing that report. The Minister also considers that a more detailed review of the Act should be undertaken by his Department within 5 years of the full implementation of the Act, i.e. on or before 1 November 2011. The Minister also accepts that the review of mental health legalisation is an ongoing process and may need to be revisited in the context of any proposed new capacity legislation or other developments. In addition, the Act must be monitored on an ongoing basis by the Department of Health and Children, in the context of legal challenges and court judgements.

The Minister is of the view that a monitoring group, consisting of representatives of the Department of Health and Children, the Department of Justice, Equality and Law Reform, the HSE, the Mental Health Commission, service providers and service users should be established. This group could identify any difficulties with the Mental Health Act 2001 as they arise and examine possible solutions. In addition, this group could have an oversight role in the linkages between the Mental Health Act 2001, the Criminal Law (Insanity) Act 2006 and contribute to any proposed capacity legislation. 


\section{KEY FINDINGS AND CONCLUSIONS}

1. The Law Reform Commission has recommended the enactment of capacity legislation. The enactment of such legislation would be helpful for the treatment and care of people with mental illness, dementia and intellectual disabilities. The current provisions relating to consent to treatment will require further consideration in the context of any new capacity legislation.

2. At this early stage of operation of the Act, it is not desirable to change the definition of "consultant psychiatrist" for the purpose of the Act, which could potentially lessen the protection afforded to the patient. (Section 2)

3. The issue of catchment areas and homeless persons is an operational matter to be addressed by the HSE. (Section 2)

4. The use and positive repute of the term "Mental Health Tribunal" in the mental health context can only be established over time. (Section 2)

5. While an amendment of section 3 ("Mental disorder") is not mandated, it may be desirable in the interest of clarity. (Section 3)

6. It is not proposed to amend the definitions of "severe dementia" and "significant intellectual disability" at this early stage of the operation of the Act. (Section 3)

7. "Best interest of the person" is a difficult concept to define in legislation and may be addressed in future court judgements. (Section 4)

8. Issues raised in relation to authorised officers are being addressed by the HSE. (Section 9)

9. It is not appropriate to amend section 10(2) of the Act to provide for the examination of the person by a registered medical practitioner 24 hours before or after the receipt of the application. To do so could lessen the level of protection for the person. (Section 10) 
10. Section 12(4) does not conflict with the separate powers of members of the Garda Síochána to arrest or detain a person pursuant to their powers under criminal law. (Section 12)

11. The Act is clear on the powers of the Garda Síochána and no change to the Act is proposed. (Section 12)

12. The Act gives members of the Garda Síochána a number of important functions regarding the involuntary admission and removal of persons to an approved centre. Training for the Garda Síochána in relation to these functions is a matter for the Garda authorities. (Sections 9, 12 and 13)

13. The HSE and hospital management should ensure that there is no delay in admission of a person from an A\&E Department, or other health settings, to an approved centre. (Section 13)

14. The assisted admissions service should be evaluated by the HSE and any difficulties identified and addressed. (Section 13)

15. Detention/involuntary admission is considered to have occurred when the consultant psychiatrist signs the admission order. (Section 13)

16. The Mental Health Commission may wish to issue guidelines advising consultant psychiatrists that a Mental Health Tribunal must be held within 21 days of making a renewal order and that any renewal order should ideally not be made until the expiry of the existing order. (Section 15)

17. Patients must be provided with adequate information on the nature, purpose and likely effects of any proposed treatment. This is provided for in section 56 and has also been addressed in the Regulations for Approved Centres. (Section 16)

18. Patients should continue to have the discretion to be admitted as a voluntary patient if he or she wishes. (Section 16)

19. As consultant manpower increases consideration should be given to reducing the 14 day time period allowed for in section $17(1)(\mathrm{c})(\mathrm{iii})$ to receive the second 
consultant's report. This would also facilitate the earlier scheduling of Mental Health Tribunals and provide earlier access by patients and their legal advisors to the second opinion reports prior to hearings. (Section 17)

20. Mental Health Tribunal hearings should take place at the earliest possible opportunity and all necessary arrangements should be made to facilitate this. Such an approach would help address the high level of detention orders being revoked prior to Mental Health Tribunals, minimise the disruption to services which can arise from the late notification, facilitate the better spacing of any second Mental Health Tribunal and alleviate difficulties experienced by both patients and service providers. (Sections 17, 18, 48, 49)

21. The Mental Health Commission and service providers should work together, on an ongoing basis, to ensure optimal collaboration in relation to the Mental Health Tribunal process. (Part 2)

22. Issues relating to access by patients to their legal representative should be addressed by the Mental Health Commission. (Sections 18, 48, 49)

23. The Mental Health Commission should consider if there is a need to develop guidance on the protocol for informing patients and service providers of the outcomes of Mental Health Tribunal reviews. (Section 18)

24. The Circuit Court appeal mechanism provided for in the Act provides the individual with the means to overturn a decision while at the same time giving due weight to the decision of the Mental Health Tribunal. (Section 19)

25. Guidance should be provided by the Mental Health Commission, where patients are being transferred, on the respective roles and responsibilities of consultant psychiatrists in transferring and receiving centres. (Section 21)

26. The Mental Health Tribunal may consult with the clinical director of the Central Mental Hospital in the course of reviewing the proposal to transfer a patient to the Central Mental Hospital. (Section 21)

27. The provision of intensive care rehabilitation units will alleviate difficulties being experienced by local services in relation to the transfer of patients to 
the Central Mental Hospital. The development of these units must be prioritised by the HSE. Issues arising in relation to patients who immediately before the expiry of their prison sentences were in the Central Mental Hospital and who continue to require treatment will be kept under review (Section 21)

28. It is not proposed to change the provisions of the Act in relation to the transfer of a patient to hospital. The Act clearly states that the detention of a person in a hospital shall be deemed to be detention for the purposes of the Act. (Section 22)

29. When a voluntary patient has a mental disorder and requires involuntary admission for treatment, the use of the normal involuntary admission procedures is preferred. The status of patients should not lightly be changed from voluntary to involuntary, and the rights of patients in this regard must be fully safeguarded. The legal scope for using the normal admission procedures under sections 9 and 10 will be examined. (Sections 23 and 24)

30. The detention of a child under section 25 requires an order of the District Court. In addition, sections $21,22,24$ to 35,37 and 47 of the Child Care Act 1991 apply to proceedings under section 25 . These provisions ensure that the child's best interests are protected. (Section 25)

31. The HSE should develop a protocol regarding the roles and responsibilities of staff involved in the admission of children under section 25 of the Act. (Section 25)

32. The responsible consultant psychiatrist would be expected to satisfy himself or herself, prior to granting absence with leave, as to where the patient will reside and how the patient can be contacted. (Section 26)

33. Clarifying what constitutes absence without leave is not a matter appropriate to legislation. Responses to absences without leave will vary and must take into account the individual circumstances of each instance. It would be helpful for the HSE and the Mental Health Commission to develop guidance on this issue. (Section 27) 
34. When an admission or renewal order has been revoked prior to the Mental Health Tribunal sitting, the purpose of a Mental Health Tribunal is to review the detention of the patient concerned to satisfy itself, insofar as is possible, that the patient was suffering from a mental disorder when the admission order or renewal order was made. The Mental Health Tribunal must also satisfy itself that the correct procedure for involuntary admission was complied with and that the patient was not unjustly detained. (Section 28)

35. In the interests of effective and efficient working, the Minister would not be in favour of the appointment of a larger Mental Health Commission to reflect the range of medical specialists in mental health. (Section 35)

36. The Act should be amended to provide for the appointment of a representative of occupational therapists to the Mental Health Commission. (Section 35)

37. It is appropriate that a multidisciplinary mental health service be inspected by a multidisciplinary inspectorate. (Section 54)

38. It would not be appropriate to amend the Act so that the rules providing for the use of electro-convulsive therapy would apply to voluntary patients. The rules should, however, guide the administration of electro-convulsive therapy to voluntary patients. (Section 59)

39. Any future review of the rules governing the use of electro-convulsive therapy undertaken by the Mental Health Commission should ensure that international best practice continues to be taken into account. (Section 59)

40. The multidisciplinary nature of modern care and treatment in mental health services will provide for inputs from all relevant team members. (Section 60)

41. It is too early to assess the impact of the review of the administration of medication to long-stay patients. This provision is a significant safeguard for patients. (Section 60) 
42. Section 61 (Treatment of children in respect of whom an order under section 25 is in force) should be amended to correctly reflect the intention of the section. (Section 61)

43. Formal links should be established between the Mental Health Commission and the Health Information and Quality Authority to facilitate the sharing and promulgation of best practice throughout health and personal social services. Formal links are also required to ensure that services are inspected by the appropriate inspectorate. (Part 5)

44. The development of approved centres for the treatment of certain groups of people is a matter for the HSE and does not require an amendment to the Act. (Part 5)

45. It is the responsibility of all service providers to ensure that all members of staff of the approved centres are aware of and adhere to their obligations and responsibilities arising from the Act. (Part 5)

46. The Act should be amended when a suitable opportunity arises to provide for the closure of approved centres. (Part 5)

47. Any guidance required regarding the duties and responsibilities of Clinical Directors should be addressed by the HSE with other service providers. (Section 71)

48. The transitional period provided for in section 72(6) should be reduced following consideration of the views of the Mental Health Commission. (Section 72)

49. It would be helpful for the Mental Health Commission to publish relevant judgments relating to the Act on its website and issue advice to service providers as required. (Section 73)

50. The Mental Health Commission should consult with the principal stakeholders in preparing the report on the operation of Part 2 under section 42(4). A more detailed review of the Act should be undertaken by the Department of Health and Children within 5 years of the full implementation of the Act, i.e. before 1 
November 2011. The review of mental health legalisation is an ongoing process and may need to be revisited in the context of any proposed new capacity legislation. In addition, the Act must be monitored on an ongoing basis by the Department of Health and Children, in the context of legal challenges and court judgements. Details of all legal challenges, hearings and court rulings should be provided to the Department of Health and Children. (Sections 42 and 75)

51. A monitoring group, consisting of representatives of the Department of Health and Children, the Department of Justice, Equality and Law Reform, the HSE, the Mental Health Commission, service providers and service users should be established to address any difficulties with the Mental Health Act 2001, to oversee the linkages between the Mental Health Act 2001 and the Criminal Law (Insanity) Act 2006 and to contribute to the development of any proposed capacity legislation. 


\section{APPENDIX 1: LIST OF SUBMISSIONS RECEIVED}

Amnesty International Irish Section

Association of Occupational Therapists of Ireland

Consultant Psychiatrists, St Ita's Hospital, Portrane

Disability Federation of Ireland

Emergency Department, St James's Hospital

Galway-Mayo Institute of Technology

Health Service Executive

Independent Hospital Association of Ireland

Irish Advocacy Network

Irish Association of Social Workers

Irish College of Psychiatrists

Irish Hospital Consultants Association

Irish Medical Organisation

Mental Health Commission

Mental Health Ireland

Mental Health Nurse Managers Ireland

National Clinical Directors in Psychiatry

National Council for the Professional Development of Nursing and Midwifery

National Disability Authority

National Federation of Voluntary Bodies

Psychiatric Nurses Association

Professor Harry Kennedy, Clinical Director, Central Mental Hospital

SIPTU Nursing Mental Health Working Group 


\section{APPENDIX 2: TIMELINE FOR THE INTRODUCTION OF THE MENTAL HEALTH ACT 2001}

$08 / 07 / 2001$

$19 / 03 / 2002$

$19 / 03 / 2002$

$02 / 08 / 2006$

$01 / 11 / 2006$

$01 / 11 / 2006$
Mental Health Act 2001 signed into law by the President

Mental Health Act 2001 (Sections 1 to 5, 7, 31 to 55) (Commencement) Order 2002 (S.I. No. 90 of 2002)

Mental Health Act 2001 (Establishment Day) Order 2002 (S.I. No. 91 of 2002). This set 5 April 2002 as the establishment day.

Mental Health Act 2001 (Commencement) Order 2006 (S.I. No. 411 of 2006). This set 1 November 2006 as the commencement date for the remaining sections of the Act.

Mental Health Act 2001 (Approved Centres) Regulations 2006 (S.I. No. 551 of 2006)

Mental Health Act 2001 (Authorised Officer) Regulations 2006 (S.I. No. 550 of 2006) 


\section{APPENDIX 3: MENTAL HEALTH TRIBUNAL STATISTICS}

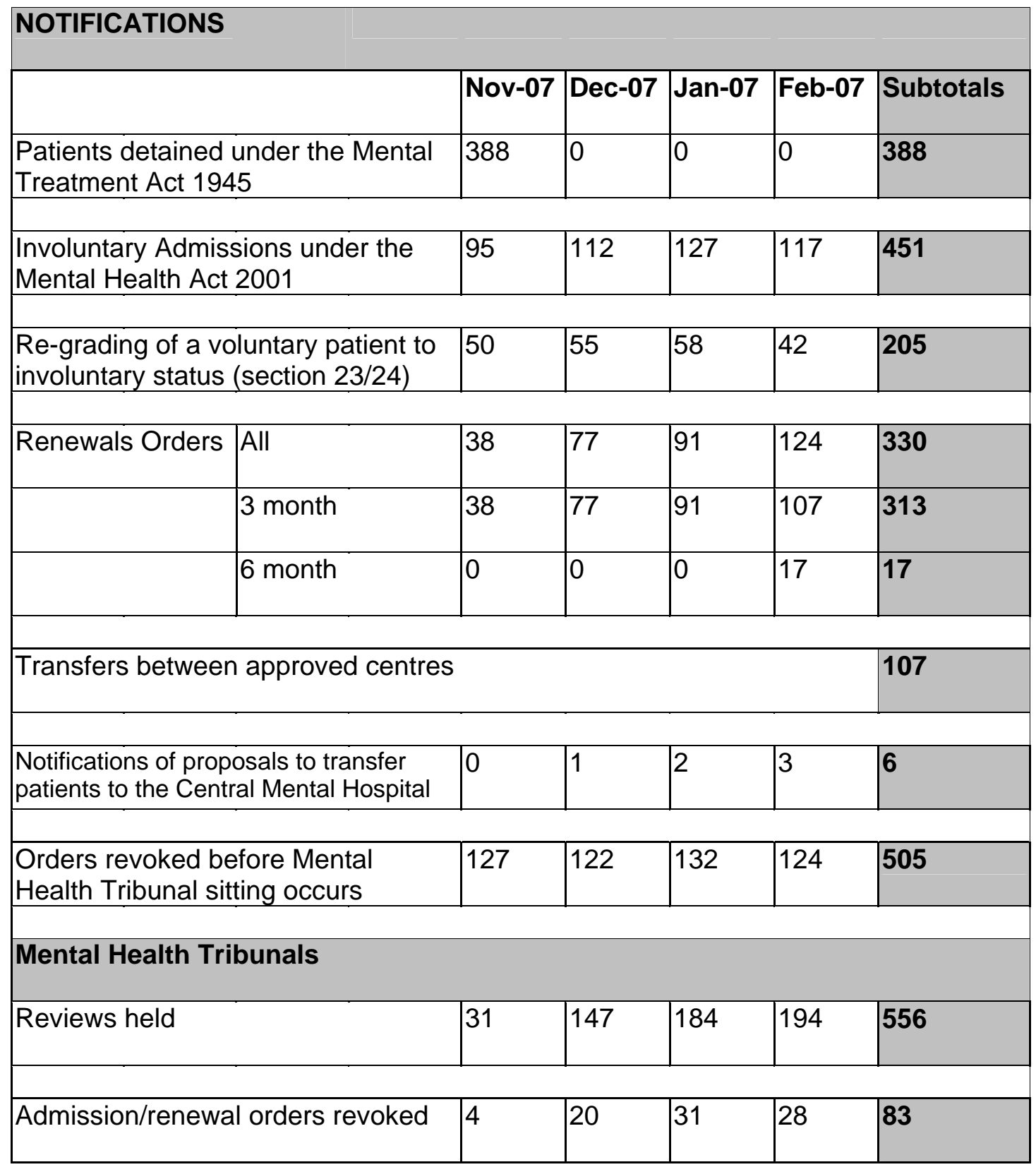


